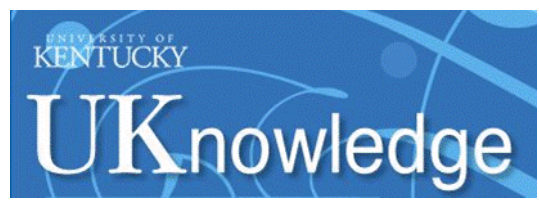

University of Kentucky

UKnowledge

\title{
An Economic Feasibility Assessment of Autonomous Field Machinery in Grain Crop Production
}

Jordan Murphy Shockley

University of Kentucky, jmshock@gmail.com

Carl R. Dillon

University of Kentucky, cdillon@uky.edu

Scott A. Shearer

The Ohio State University

Follow this and additional works at: https://uknowledge.uky.edu/agecon_facpub

Part of the Agricultural Economics Commons

Right click to open a feedback form in a new tab to let us know how this document benefits you.

\section{Repository Citation}

Shockley, Jordan Murphy; Dillon, Carl R.; and Shearer, Scott A., "An Economic Feasibility Assessment of Autonomous Field Machinery in Grain Crop Production" (2019). Agricultural Economics Faculty Publications. 15.

https://uknowledge.uky.edu/agecon_facpub/15

This Article is brought to you for free and open access by the Agricultural Economics at UKnowledge. It has been accepted for inclusion in Agricultural Economics Faculty Publications by an authorized administrator of UKnowledge. For more information, please contact UKnowledge@lsv.uky.edu. 


\section{An Economic Feasibility Assessment of Autonomous Field Machinery in Grain Crop Production}

\section{Digital Object Identifier (DOI)}

https://doi.org/10.1007/s11119-019-09638-w

\section{Notes/Citation Information}

To be published in Precision Agriculture, p. 1-18.

(C) Springer Science+Business Media, LLC, part of Springer Nature 2019

This is a post-peer-review, pre-copyedit version of an article published in Precision Agriculture. The final authenticated version is available online at: https://doi.org/10.1007/s11119-019-09638-w.

The copyright holder has granted the permission for posting the article here. 
Authors:

Jordan M. Shockley (Corresponding)

University of Kentucky

Department of Agricultural Economics

410 C.E. Barnhart Building

Lexington, KY 40526

Email: jordan.shockley@uky.edu

Phone: 859-218-4391

Carl R. Dillon

University of Kentucky

Department of Agricultural Economics

403 C.E. Barnhart Building

Lexington, KY 40526

Scott A. Shearer

The Ohio State University

Department of Food, Agricultural and Biological Engineering

200A Agricultural Engineering

590 Woody Hayes Drive

Columbus, OH 43210 


\begin{abstract}
A multi-faceted whole farm planning model is developed to compare conventional and autonomous machinery for grain crop production under various benefit, farm size, suitable field day risk aversion, and grain price scenarios. Results suggest that autonomous machinery can be an economically viable alternative to conventional manned machinery if the establishment of intelligent controls is cost effective. An increase in net returns of $24 \%$ over operating with conventional machinery is found when including both input savings and a yield increase due to reduced compaction. This study also identifies the break-even investment price for intelligent controls for the safe and reliable commercialization of autonomous machinery. Results indicate that the break-even investment price is highly variable depending on the financial benefits resulting from the deployment of autonomous machinery, farm size, suitable field day risk aversion, and grain prices. The maximum break-even investment price for intelligent, autonomous controls is nearly U.S. $\$ 500,000$ for the median days suitable for fieldwork when including both input savings and a yield increase due to reduced compaction.
\end{abstract}

KEYWORDS: economics, mathematical programming, machinery selection, whole farm planning 


\section{An Economic Feasibility Assessment of Autonomous Field Machinery in Grain Crop Production}

Over the years, the dominant trend in agricultural machinery has been toward the use of larger sizes of conventional equipment in crop production. One of the primary reasons farmers desire larger equipment is to benefit from economies of size. Specifically, farmers can become more economically competitive by substituting capital for labor, thereby reducing per hectare labor costs. Additionally, larger equipment can mitigate the risks associated with untimely operations due to unfavorable weather conditions. Other factors such as the need to compensate for the declining and seasonal availability of a skilled agricultural workforce or producers' desire for more leisure time are also possible explanations for the trend to larger machines. However, as the size of agricultural machines continues to increase, consequences that are detrimental to both the operator and environment arise. For the operator, controlling large implements on irregular terrain and moving equipment between fields along narrow public thoroughfares is problematic at best. Furthermore, soil compaction seems to be largely ignored as ballasted mass increases in direct proportion to engine size. Moreover, larger equipment leads to input metering and application errors with overlap and velocity variations across the implement width when turning. Some researchers are concerned that producers may not be capable of achieving uniform application with increasing equipment size (Luck et al., 2011). Autonomous machinery may offer the potential to reverse the deleterious trends of larger equipment while preserving the timeliness advantage.

The replacement of large manned machines with smaller autonomous machinery represents a paradigm shift that will lead to substantive changes in the structure of agriculture. The implications of autonomous machinery likely will be profound and encompass a variety of disciplines. At the macroeconomic level, replacing human operators with advanced technology will influence labor markets. Alternately, at the microeconomic level, issues pertaining to economies of size and scope, capital labor substitution, environmental quality, and rural development will be influenced by adopting autonomous machinery. Aside from economics, the implementation of autonomous machinery will create new sociological dynamics by allowing more leisure and family time for the once constrained farm operators. Furthermore, by removing the operator from the tractor, farm safety (i.e., exposure to chemicals and machinery related accidents such as tractor overturn) will improve. Autonomous machinery will also entice a technologically savvy younger generation (e.g. Generations Y and Z) to farming as an occupation. However, none of the above issues are of concern if autonomous machinery is not profitable for producers.

The potential economic benefits from utilizing autonomous machines are numerous. Replacing a human operator with automated controls will reduce average labor requirements and associated costs. Furthermore, autonomous agricultural field operations could occur 24 hours per day and seven days a week during times of favorable field conditions thereby mitigating the risk associated with untimely field 
operations. By utilizing smaller machines with intelligent controls, the metering and distribution of inputs will improve thereby eliminating off-target and off-rate application errors which increases use-efficiency, reduces costs, and improves crop quality. With the reduction in machine size and inherent weight advantage comes a reduced potential for soil compaction. Coupled with the ability to improve chemical, fertilizer and fuel use efficiency, the environmental impacts of autonomous machinery will be substantial especially to the extent they can be coupled with variable rate application (Scheiffer and Dillon, 2015). Hence, the utilization of autonomous machinery could develop into a more profitable approach to production agriculture.

The opportunity rarely presents itself in which economics can influence the initial development of a technology. A thorough economic evaluation of autonomous machinery systems will provide engineers with valuable information regarding the costs and benefits required for autonomous machinery to compete with conventional machinery. One of the largest challenges facing the machinery industry/engineers is how much to invest in the development of intelligent controls necessary for the implementation of autonomous machinery. A key decision tool for manufacturers is the break-even investment price. This represents the maximum price that manufacturers can charge for a technology, (in this case intelligent controls) at which a producer is indifferent between operating with conventional versus autonomous machinery. However, other important factors are embedded within the product price such as the profit to the firms, additional implementation costs (e.g. insurance, legal, product support, and subscription costs), and opportunity costs from switching from conventional to autonomous machinery (e.g. learning curve cost). Therefore, the price which manufacturers could charge producers will likely be some fraction of the break-even investment price.

The goal of this project is to assess the economic viability of performing agricultural field operations autonomously by completing the following objectives: (1) develop a whole farm planning model for grain production that allows comparison between conventional and autonomous machinery systems, (2) determine the optimal conventional machinery complement necessary to perform agricultural field operations common in grain production, (3) determine the optimal complement of autonomous machines necessary to perform the same field operations, (4) determine the break-even investment price for intelligent, autonomous controls, (5) demonstrate the ability of the model to incorporate additional anticipated economic benefits that will accrue to autonomous machinery and the impact on net returns and break-even investment price, (6) determine the impact of farm size on the above objectives, (7) determine the impact of suitable field day uncertainty on machinery selection, net returns, and break-even investment price, and (8) determine the impact of grain price on machinery selection, net returns, and break-even investment price. This study is an expansion of Shockley and Dillon (2018) with the inclusion of new data and evaluating suitable field day uncertainty on machinery selection, net returns, and break-even investment price. 
Furthermore, additional sensitivity analyses are included to evaluate the feasibility of autonomous machinery in grain crop production.

\section{Autonomous Machinery Development}

Introducing smaller, light-weight machinery that can perform agricultural field operations may prove to be a realistic option for producers in the future. These machines will likely operate in fleets and utilize intelligent controls to perform production operations like seeding, spraying, fertilizing, and harvesting. Recently, researchers and engineers have developed various prototype vehicles capable of autonomous operation. These prototypes have the ability to accommodate various attachments such as tillage tools, seeders, and sprayers, much like an operator driven tractor. Several studies have investigated the development, design, and implementation of autonomous machinery (Blackmore et al., 2004; Blackmore and Blackmore, 2007; Vaugioukas, 2007; Vaugioukas, 2009). Further research has been conducted to analyze the accuracy, steering, and performance of various autonomous prototypes (van Henten et al., 2009; Marchant, 1997; Bak and Jakobsen, 2004). Other studies have concentrated specifically on autonomous weed detection and management (Gottschalk et al., 2009; Ruckelshausen et al., 2009; Pedersen et al., 2007; Pedersen et al., 2006; Astrand and Baerveldt, 2002). Harvesting grain will be very difficult to perform with smaller, light-weight autonomous machinery due to the volume of biomass to be processed and removed from the field. As a result, harvest operations may be the last to the automated.

The most difficult issue facing engineers in the development of autonomous machines is making them safe and reliable. Researchers and engineers have begun to address this problem by equipping the autonomous machine with perception and sensing technologies for obstacle detection; interrupt and error handling routines; and multi-level control architectures to optimise system behavior (Griepentrog et al., 2009; Vougioukas, 2009; Rackelshausen et al., 2009; Pitla et al. 2010a; Pitla et al. 2010b). It is recognized that safety is paramount to the successful commercialization and deployment of autonomous field machinery. However, the solution to achieve satisfactory levels of safety and reliability could be costly. In this context, the break-even investment price will serve as a useful guide for researchers and engineers developing such intelligent controls and control architectures.

Economists have also investigated the potential of autonomous vehicles for agricultural operations. Goense (2005) analyzed an autonomous row crop cultivator to determine the effect of the size of autonomous implements on mechanization costs. Pedersen et al. (2006) compared the costs and potential benefits of an autonomous machine that was capable of field scouting cereal crops. Partial budgeting was used to determine that autonomous field scouting reduced the costs by $20 \%$, but profitability was sensitive to initial investments and the annual costs for the GPS system. In 2007, Pederson et al. conducted an investigation into autonomous weeding and grass cutting. Partial budgeting was used to compare the cost changes to conventional practices and determine if autonomous machinery was cost-effective. Providing 
adequate safety measures and control systems could be implemented at a reasonable cost, autonomous weeding and grass cutting could be a viable alternative to conventional systems. Because of the infancy of autonomous field machinery and lack of suitable economic investigations, numerous research opportunities exist that will provide valuable insight into the development and profitability of this technology.

\section{Economic Model}

The introduction of autonomous field machinery will produce complex interactions affecting not only machinery management but also changes to labor requirements, timing of field operations, and other cropping practices. To facilitate the analysis, a decision-making framework is established. The model considers the entire farming system and allows for changes in cropping patterns, machinery complements, and labor requirements. A common decision-making framework in farm management is a whole farm planning model. Whole farm planning models have the ability to capture interactive effects that occur between elements within the model that most decision-making aids, such as partial budgeting, ignore. Also, the attention to detail and complexities of a whole farm model provide a more accurate depiction of changes that occur at the farm level. Given this, a whole farm planning model is ideal for comparing machinery alternatives.

One of the main objective of this study is to develop a multi-faceted whole farm planning model to accomplish a comparison for conventional versus autonomous machinery options for grain production. A mixed integer mathematical programming formulation is developed that incorporates three optimization models: machinery selection, resource allocation, and sequencing which follows the framework by Danok et al. (1980). The machinery selection component is the foundation of the whole farm planning model and provides insight into the optimal size of conventional machinery and the optimal number of autonomous vehicles required to perform specific agricultural field operations common in grain crop production. When comparing conventional versus autonomous equipment, machinery costs and performance data differentiate the two analyses and are reflected when optimizing net returns while using the same model formulation. The underlying machinery selection model consists of the following objective function and constraints:

(1) $\quad \operatorname{Max} \overline{\mathrm{NR}}$

Subject to:

(2) $\quad \sum_{Y R} \frac{1}{N} N R_{Y R}-\overline{N R}=0$

(3) $\sum_{E} P_{E} S A L E S_{E, Y R}-\sum_{E} \sum_{P} \sum_{M} \sum_{A} \sum_{W K} O P_{M} A C T_{E, P, M, A, W K}-\sum_{M} O W N_{M} * B U Y_{M}-$

$\sum_{E} \sum_{V} \sum_{P} \sum_{S} V C_{E} P R O D_{E, V, P, S}-N R_{Y R}=0 \quad \forall Y R$

$$
\begin{aligned}
& \sum_{E} \sum_{V} \sum_{P} \sum_{S} E X P Y L D_{C, E, V, P, S, Y R} P R O D_{E, V, P, S}-S A L E S_{E, Y R}=0 \quad \forall C, Y R \\
& \sum_{M} B U Y_{M}=1 \quad \text { Under Conventional Machinery Selection } \\
& B U Y_{M=T}-B U Y_{I \subseteq \mathrm{M}} \geq 0 \quad \forall I \quad \text { Under Autonomous Machinery Selection }
\end{aligned}
$$


Equation 1 represents the objective function of the model, which is to maximize average net return $(\overline{N R})$. Equations 2-6 define relevant variables and impose various constraints related to the machinery selection portion of the mixed integer programming model. To determine the maximum average net returns, both net returns and the mean of those net returns must be defined. The mean net returns are defined as the sum of net returns $\left(N R_{Y R}\right)$ estimated each year (YR) divided by the total number of years $(\mathrm{N})$ considered, which is 30 years for this model (Equation 2). The net returns per year equal the total sales minus the total costs (Equation 3). Total sales equal the amount of each enterprise (E) sold per year in kilograms $\left(S A L E S_{E, Y R}\right)$ multiplied by the price per kilogram of each enterprise $\left(P_{E}\right)$. Total costs are determined from machinery operating costs, machinery ownership costs, and all other variable costs of production (e.g. seed cost, chemical cost, fertilizer costs, etc.). Total operating costs per machine equal the cost per hectare to operate machine $\mathrm{M}\left(O P_{M}\right)$ multiplied by the total number of hectares covered when performing the various production activities $\left(A C T_{E, P, M, A, W K}\right)$ common in grain production. Each production activity (e.g. planting, spraying, fertilizing, and harvesting) is defined by enterprise $(\mathrm{E})$, planting date $(\mathrm{P})$, and the appropriate machine (M) to conduct the activity (A) during the specified week(s) (WK). The specification of planting date to define production activity is clarified in the forthcoming sequencing discussion. Total machinery operating costs are determined by summing these expenses across all machines.

To calculate the ownership cost, a machine must be purchased $\left(B U Y_{M}\right)$ before the annual ownership cost of the machine $\left(O W N_{M}\right)$ will incur. The sum of all ownership costs of purchased machines determine the total machinery ownership costs of production. Furthermore, the total of all other variable costs of production equal the variable costs per hectare of production $\left(V C_{E}\right)$ for each enterprise multiplied by how many hectares of each enterprise is produced $\left(P R O D_{E, V, P, S}\right)$ and summed across enterprises. The number of hectares of each enterprise $(\mathrm{E})$ produced is defined by variety $(\mathrm{V})$, planting date $(\mathrm{P})$, and soil type (S). These components combine to identify per year and average net returns.

To calculate yearly net returns, total sales (Equation 4) is defined as the estimated yields in kilograms per hectare $\left(E X P Y L D_{E, V, P, S, Y R}\right)$ multiplied by how many hectares of each enterprise is produced $\left(P R O D_{E, V, P, S}\right)$. The inclusion of estimated yields based on variety, plant population, and soil type allow for optimal crop planning by determining the area allotment for each enterprise. More details regarding implementation of estimated yields are provided in the next section.

Purchase constraints are also required within the machinery selection portion of the model (Equations 5 and 6). For the selection of conventional machinery, the model is required to choose one machinery complement (Equation 5). Each complement contains the necessary equipment to complete the agricultural field activities, while the combination of varying equipment sizes differentiate each complement. Equation 5 is only necessary when selecting conventional machinery. On the other hand, the selection of autonomous machinery requires different purchase constraints (Equation 6). Since autonomous 
machinery is still in the developmental stage, only one machinery complement is contained in the choice set (e.g. an autonomous prototype). Instead of selecting the optimal size of machinery (conventional analysis), the autonomous analysis selects the optimal number of autonomous machines to complete the agricultural field activities. Equation 6 specifies that the number of autonomous vehicles must equal or exceed the optimal number of implements for every particular machine implement I. For example, if five planters, three sprayers and four fertilizers are optimal, then the farmer must own five or more autonomous tractors.

The mixed integer programming model is also constrained by limitations associated with resource allocation and the competition among scarce resources.

$$
\begin{aligned}
& \sum_{V} \sum_{P} \sum_{S} P R O D_{E, V, P, S} \leq\left(\frac{1}{Y R S}\right) * A C R E \quad \forall E \\
& \sum_{E} \sum_{P} \sum_{A} F C_{M, A} A C T_{E, P, M, A, W K}-\text { TIME }_{W K} B U Y_{M} \leq 0 \quad \forall W K, M \\
& \text { SOILRATIO }_{S_{i}} P R O D_{E, V, P, S_{j}}-\operatorname{SOILRATIO}_{S_{j}} P_{R O D_{E, V, P, S_{i}}}=0 \quad \forall S_{i, j, i \neq j}, E, V, P
\end{aligned}
$$

One of the limiting resources in agricultural production is land; therefore, a land constraint is required so that the area (ha) designated to producing each enterprise $\left(P R O D_{E, V, P, S}\right)$ does not exceed the designated amount of available cropland for the study (ACRE). Since crop rotation is common in grain production, there exists a rotation component, in which the land area designated to each enterprise is proportionate to the number years in rotation (YRS). To employ the rotational component within the model, a categorization matrix $R O T A T E_{E}$ is required to identify the enterprises in rotation.

Another limiting resource in agricultural production is time; therefore, a suitable field time constraint is required (Equation 8). This constraint ensures that the machinery operating time (h) for each production activity, designated by the field capacity of the machine $\left(F C_{M, A}\right)$ in ha $\mathrm{h}^{-1}$ for each production activity multiplied by the total area (ha) of each production activity, does not exceed the amount of suitable field hours available each week $\left(T I M E_{W K}\right)$. However, the complete complement must be purchased to operate during those suitable field hours. Therefore, the total amount of time to complete each activity must be less than the available suitable field hours. Suitable field day uncertainty is examined using the chance-constrained formulation developed by Charnes and Cooper (1959). The Charnes and Cooper (1959) formulation was developed to evaluate right-hand side uncertainty and was utilized to evaluate suitable field day risk in other whole-farm models (Dillon, 1999; Shockley et al., 2011).

Since the model incorporates yield data that is estimated on various soil types (S), a soil balance constraint is required (Equation 9). This constraint ensures that the optimal area (ha) of each enterprise produced is proportionate to the ratio of soils in the study area $\left(\operatorname{SOILRATIO}_{S}\right)$. For example, if the study area consists of two soil types and the ratio was $4: 1$, this constraint ensures that the estimated yields on the two soil types reflects this ratio when determining total yields for the study area. 
Finally, grain crops are produced through a process involving multiple field activities (e.g. spraying, planting, fertilizing, and harvesting). Each process is not only competing for resources, but typically involves a sequence in which one process must be completed before the next begins. Therefore a sequential component is incorporated into the mixed integer programming model (Equation 10).

$$
\sum_{E} \sum_{V} \sum_{S} P R O D_{E, V, P, S}-\sum_{E} \sum_{M} \sum_{A} \sum_{W K} A L L O W_{E, P, A, W K} A_{C T, P, M, A, W K} \leq 0 \quad \forall P
$$

When determining the sequence of events, a reference point is designated. For this model, all activities are performed either before or after planting (P) a specific enterprise. Each production activity must occur during an ideal time frame $\left(A L L O W_{E, P, A, W K}\right)$ for the study area. This equation guarantees all production activities are completed in the correct sequence, as well as during the appropriate week. Equations 1-10 comprise the mixed integer mathematical programming formulation that is employed for evaluating conventional versus autonomous machinery.

Combining the three elements above form a unique and complex whole farm planning model that is capable of jointly selecting optimal machinery management and crop production management. The focus of this study is solely on the machinery selection to provide valuable information to engineers and researchers with regard to autonomous machinery cost structure and implementation.

\section{Case Analysis Framework}

To properly assess a grain farmers' optimal machinery selection decision as required for the second and third study objectives, the underlying production environment is established. This investigation is modeled after a typical western Kentucky farm producing corn and soybeans in a two year rotation. Both enterprises are produced under no-till conditions for an 850 ha farm. This farm size depicts the upper one third in management as represented by net farm income of grain producers in the Ohio Valley region of Kentucky enrolled in the Kentucky Farm Business Management Program (Pierce, 2018). The yields estimated for this case study uses the Decision Support System for Agrotechnology Transfer (DSSAT), a biophysical simulation model (Jones, 2003). Utilizing soil surveys from the National Resources and Conservation Service, four predominant soil types are in western Kentucky: deep silt loam, shallow silt loam, deep silt clay, and shallow silt clay. The soil ratios are $60 \%, 15 \%, 20 \%$, and $5 \%$, respectively. Validations are performed and the resulting simulated yields are thought representative of a Western Kentucky grain farm. For this investigation, a subset of the yield data from Shockley et al. (2011) is employed.

Specific sequences of field operations must occur for the production of corn and soybeans. For corn, the sequence of operations is pre-plant fertilizer/lime application, burndown herbicide treatment, planting, pre-emergence herbicide application, post-emergence herbicide application, nitrogen application, and harvest. Soybean production requires pre-plant fertilizer/lime application, burndown herbicide treatment, planting, post-emergence herbicide application, insecticide treatment, and harvest. These 
production practices for both corn and soybeans are consistent with University of Kentucky Cooperative Extension Service Bulletins (2008). In addition, this bulletin provides input application rates and timing for performing specific operations which, in turn are applied to the whole farm planning model. Harvest and the application of phosphorous, potassium and lime are assumed to be custom hired.

To complete these production activities, the appropriate conventional and autonomous machinery complements are selected. A conventional machinery complement consists of a tractor, planter, sprayer, and fertilizer applicator. The machinery choice set represents typical options available to a grain producer (Table 1). All data for conventional machinery are compiled from the Mississippi State Budget Generator (Laughlin and Spurlock, 2007), which complies with ASABE Standards D497.7 and EP496.3, and reflects 2018 costs. Specifically, operating costs (fuel, repair and maintenance, and labor), annual costs of ownership, and the performance rates of the implements are utilized in the machinery selection decision. In addition, the Mississippi State Budget Generator is used to estimate all other variable costs based on costs paid by Kentucky producers in 2018 .

Table 1. Conventional options to compose machinery complements for development of the choice set under the case study.

Tractor: $105 \mathrm{hp}, 130 \mathrm{hp}, 190 \mathrm{hp}, 300 \mathrm{hp}, 400 \mathrm{hp}$

Sprayer (Broadcast): $8.2 \mathrm{~m}, 12.2 \mathrm{~m}, 15.2 \mathrm{~m}, 18.3 \mathrm{~m}, 27.4 \mathrm{~m}, 36.6 \mathrm{~m}$

No-Till Split-Row Planter: 4-row, 6-row, 8-row, 12-row, 16-row, 24-row

Liquid Fertilizer Applicator: 6-row, 8-row, 12-row

Note: All potential solutions followed appropriate draft and equipment matching requirements.

Economic modeling of autonomous machinery is scarce because of the lack of necessary data, especially when considering machinery selection decisions. Fortunately, faculty members in the University of Kentucky Department of Biosystems and Agricultural Engineering developed autonomous tractor prototypes. This study used actual costs and performance data based on one of these prototypes (Table 2). The base autonomous prototype machine is designed to be fitted with interchangeable implements (planter, sprayer, and fertilizer applicator), similar to a conventional tractor. The ownership costs of the autonomous tractor and implements are annualized to include depreciation and the opportunity cost of capital invested. Since optimal intelligent, autonomous controls have yet to be established, the cost of such controls is excluded from those presented in Table 2. Therefore, this study determines a break-even investment price (Objective 4) to guide the development of intelligent, autonomous controls. Options other than purchasing the equipment (i.e. short-term rental, leasing, and custom hiring) are excluded from this study because of the lack of appropriate data. Depreciation is calculated using the straight-line method with an assumed three year useful life and salvage value of $50 \%$ of the cost for the autonomous vehicle (without controls) 
and implements. ${ }^{1}$ A shorter useful life was assumed as compared to conventional machinery (eight year useful life) to reflect both the smaller size of autonomous machinery and intelligent controls required for operation. Therefore, a three year useful life is similar to a computer/software rather than the economic life used with conventional machinery. However, if the useful life is similar to conventional machinery, the annual ownership cost would decrease (U.S.\$2,558) per tractor and the break-even investment cost of intelligent controls calculated herein will increase. The opportunity cost of capital investment is calculated using an $8 \%$ interest rate which is consistent with other studies evaluating precision agriculture technologies (Shockley et al., 2011). In addition, labor equivalent to that required with conventional machinery is removed from the autonomous investigation. There is anticipated incidental labor costs associated with refilling seed, chemical, and fertilizer, as well as transporting the machines to different locations, but these are not addressed in this study. In addition, there is an anticipated opportunity cost associated with the implementation of the new machinery paradigm, which is not included in this investigation.

Table 2. Cost and performance data related to the autonomous prototype developed by the University of Kentucky and estimates of implement specifications utilized for the case analysis.

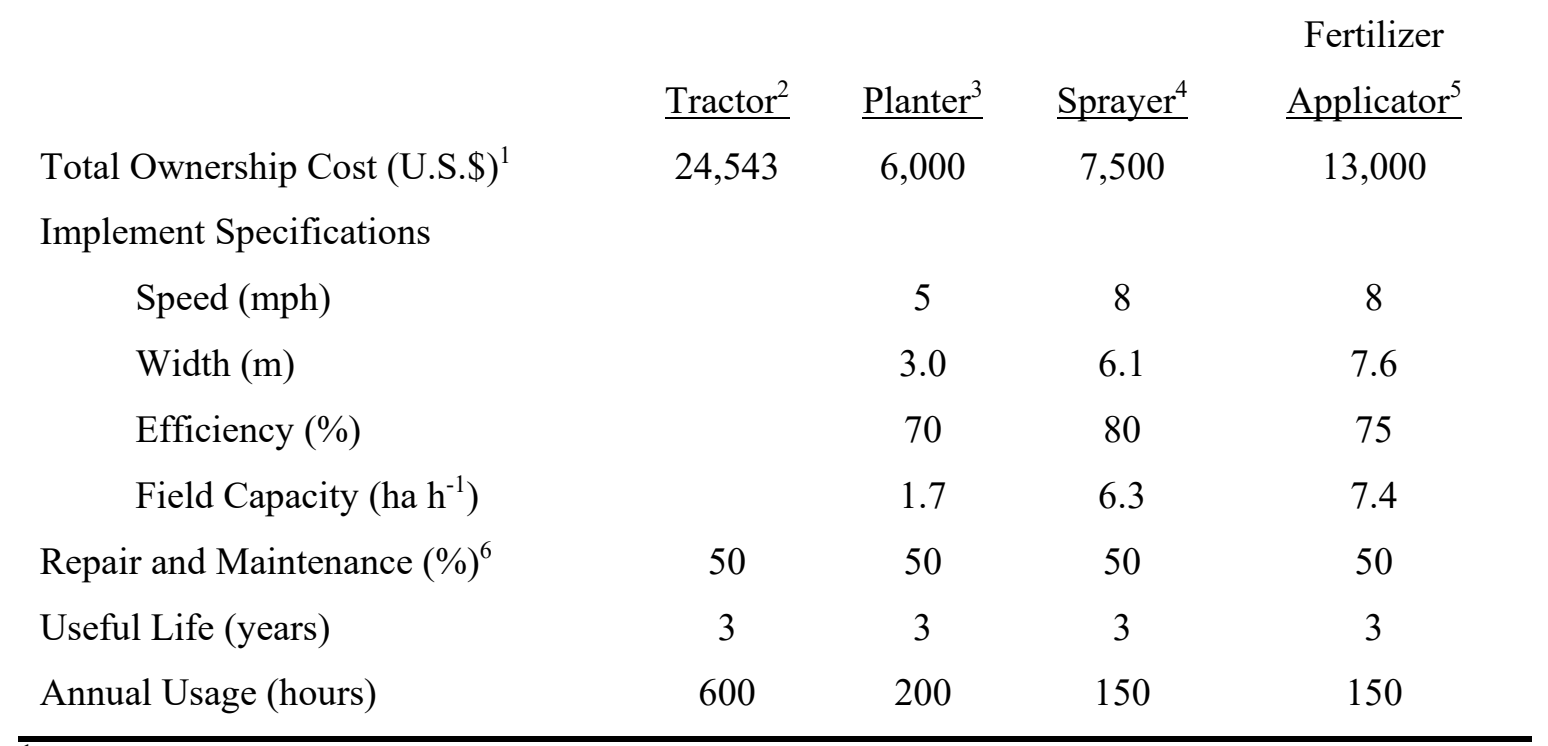

${ }^{1}$ Total ownership costs exclude the costs of intelligent controls for automation.

${ }^{2}$ The tractor was a 46 hp KAT II in which costs composed of a U.S.\$3,600 engine, U.S.\$2,760 wheel motors, U.S.\$900 pumps, U.S.\$1,800 hydraulics, U.S.\$720 wheels/tires, U.S.\$750 electronics, and U.S.\$14,013 for the structure. In addition, the tractor had fuel use rate of $12.31 \mathrm{~h}^{-1}$

\footnotetext{
${ }^{1}$ The annual costs for owning an autonomous machinery was calculated as follows using straight-line depreciation plus opportunity cost of the capital investment: [((Total Investment - Salvage Value)/(Useful Life)) + ((Total Investment + Salvage Value)*Interest Rate)/2].
} 
${ }^{3}$ A row seeder attachment was estimated at U.S.\$1,500 per row.

${ }^{4}$ The sprayer was equipped with a 1514 l (400 gal) tank.

${ }^{5}$ The fertilizer applicator consisted of a spinner and apron chain mechanism with a $1814 \mathrm{~kg}$ spreader box.

${ }^{6}$ Conventional machinery repairs and maintenance range from $15 \%$ of the purchase price for tractors to $80 \%$ of the purchase price for fertilizer applicators.

Additional data includes determining suitable field time $\left(T I M E_{W K}\right)$ for both conventional and autonomous analyses. The total available hours per week is dependent on the number of probable suitable field days and the hours worked per day. The number of probable suitable field days per week for the study area is based on Shockley and Mark (2017). Utilizing the Charnes and Cooper (1959) formulation, three risk levels are evaluated for investigating Objective 7, 50\% (risk neutral), 60\% (mild risk aversion), and $75 \%$ (moderate risk aversion) likelihood for days suitable for fieldwork. The conventional analysis is limited by the human operator; therefore, only 13 hours per day is assumed (Shockley et al., 2011). On the other hand, autonomous machinery can operate 24 hours per day, which is assumed for this study (Pedersen et al., 2006; Blackmore et al., 2004). The overall machinery selection model is consistent across both types of machines with respect to the tasks performed, with the technical data differentiating the two analyses.

\section{Results}

\section{Conventional versus Autonomous Machinery Results: Base Comparison}

Given the framework above, the models developed for Objective 1 select the optimal conventional machinery complement from the inventory of available equipment, and also select the optimal number of autonomous machines to perform the same sequence of field operations for an 850 hectare grain farm (Table 3). For Objective 2, the optimal size of conventional machinery for an 850 hectare grain farm are a $130 \mathrm{hp}$ tractor, an 8-row planter, an 8-row fertilizer applicator, and an 18.3 meter sprayer. For Objective 3, the model suggests that one autonomous tractor and accompanying implements (one each planter, sprayer and fertilizer) are necessary. When comparing autonomous and conventional machinery for the base risk neutral case (Table 3), the net returns are U.S.\$5,993 (1\%) greater when operating with autonomous machinery. The majority of additional returns are attributed to a reduction in machinery ownership and operating costs. There is a $28 \%$ reduction in machinery ownership costs and a $34 \%$ reduction in machinery operating costs. Within these operating cost savings, reduced labor expense amounts to U.S. \$7,277 and reduced fuel expense amounts to U.S. \$1,633. Notably, planting time shifts attributable to the smaller autonomous equipment did lead to slight reductions in average farm yields from the conventional machinery case. Consequently, the reduced revenues from farm sales do reduce the impacts of lower 
machinery expenses realized on farm net returns. The net result does demonstrate the potential profitability of autonomous machinery.

Since the investment costs of autonomous machinery did not include the cost of intelligent controls, the difference in net returns (U.S.\$5,993) represents a "maximum annual willingness to pay" by producers for intelligent, autonomous controls. Specifically, this investment price reflects what a manufacturer may be able to charge for intelligent controls in addition to the explicitly modeled U.S.\$24,543 per autonomous tractor for which a producer would be indifferent between operating with conventional versus autonomous machinery, ceteris paribus. This value considers the investment price impacts on both ownership (depreciation and interest) and operating costs (repairs and maintenance). For this scenario, the break-even investment price for intelligent controls is U.S.\$26,128 (Objective 4).

Table 3. Machinery selection and corresponding economic results for both conventional and autonomous machinery with the inclusion of various selected input cost reductions and yield increases due to reduced compaction for an 850 hectare grain farm under risk neutral median 50\% likelihood for days suitable for fieldwork.

\begin{tabular}{|l|c|cccc|}
\hline & Conventional & \multicolumn{4}{|c|}{ Autonomous (Benefits Assumed) } \\
\hline Scenario & Base & Base & Cost Only & Yield Only & Cost \& Yield \\
Tractors(s) & $130 \mathrm{hp}$ & $1-46 \mathrm{hp}$ & $1-46 \mathrm{hp}$ & $1-46 \mathrm{hp}$ & $1-46 \mathrm{hp}$ \\
Planter(s) & 8 row & $1-4 \mathrm{row}$ & $1-4 \mathrm{row}$ & $1-4$ row & $1-4$ row \\
Fertilizer App. & 8 row & $1-7.6 \mathrm{~m}$ & $1-7.6 \mathrm{~m}$ & $1-7.6 \mathrm{~m}$ & $1-7.6 \mathrm{~m}$ \\
Sprayer & $18.3 \mathrm{~m}$ & $1-6.1 \mathrm{~m}$ & $1-6.1 \mathrm{~m}$ & $1-6.1 \mathrm{~m}$ & $1-6.1 \mathrm{~m}$ \\
& & & & & \\
Input Cost Reduction & - & $0 \%$ & $10 \%$ & $0 \%$ & $10 \%$ \\
Yield Increase & - & $0 \%$ & $0 \%$ & $7 \%$ & $7 \%$ \\
& & & & & \\
Avg. Net Returns (U.S.\$) & 600,057 & 606,050 & 636,979 & 688,361 & 719,290 \\
Min. Net Returns (U.S.\$) & 318,674 & 345,094 & 376,023 & 395,716 & 426,645 \\
Max. Net Returns (U.S.\$) & 858,863 & 791,930 & 822,859 & 934,515 & 965,443 \\
Std. Dev. Net Returns (U.S.\$) & 132,061 & 122,871 & 122,871 & 137,868 & 137,868 \\
Coef. of Var. Net Returns (\%) & 22.01 & 20.27 & 19.29 & 20.03 & 19.17 \\
Selected Input Costs (U.S.\$) ${ }^{1}$ & 309,287 & 309,287 & 278,358 & 309,287 & 278,358 \\
B-E Invest Price (U.S.\$) & - & 26,128 & 160,995 & 96,825 & 130,737 \\
& & & & & 10,972 \\
Avg. Corn Yield (kg ha ${ }^{-1}$ ) & 10,293 & 10,150 & 10,150 & 10,972 & 4,480 \\
Avg. Soybean Yield (kg ha ${ }^{-1}$ ) & 4,188 & 4,181 & 4,181 & 4,480 & \\
\hline
\end{tabular}


${ }^{1}$ Selected input costs are for herbicide, insecticide, seed, and nitrogen.

${ }^{2} \mathrm{~B}$-E refers to break-even.

Based upon the data and assumptions described above, an investment price of U.S.\$26,128 leads to annualized autonomous machine costs of U.S.\$4,355 for depreciation, U.S.\$1,568 for interest, and U.S.\$70 for repairs and maintenance for a total of U.S.\$5,993. Recall that this represents the maximum a manufacturer can charge for intelligent controls as discussed in the introduction; therefore, the actual charge will likely be some fraction of this price. It is important to note that these results are representative of this particular case study and autonomous prototype examined.

\section{Inclusion of Additional Anticipated Economic Benefits}

Beyond the results for the base comparison, this study focuses on two of the most anticipated additional quantitative benefits that could accrue through utilization of autonomous machinery: reduced selected input costs and increased yields from reduced compaction (Objective 5). The estimates used for demonstrating the ability of the model to incorporate such benefits are determined from literature pertaining to various autonomous prototypes (e.g. Pedersen et al., 2006; Blackmore et al., 2004; Rackelshausen et al., 2009; van Henten et al., 2009).

The reduction in selected input costs is considered one of the primary benefits of utilizing autonomous machinery. For this study, the input costs impacts by autonomous machinery included herbicide, insecticide, seed, and nitrogen costs. Previous studies concluded a broad range of input cost reduction depending on field operation and intelligent control methods (Pedersen et al., 2006; Blackmore et al., 2004; Rackelshausen et al., 2009; van Henten et al., 2009). Pendersen et al., (2007) reported up to a $90 \%$ reduction in herbicide cost alone for an autonomous micro-sprayer because of its ability to recognize individual weeds and target herbicide application. However, Pendersen et al., (2006) reports and estimated average reduction in input cost from autonomous machinery of $20 \%$, and ranging from $12 \%$ to $25 \%$. Other Furthermore, current precision agriculture technologies such as automated steering and section control reduce input costs by $10 \%$ (Shockley et al., 2011; Shockley et al., 2012). Therefore, a conservative estimate of a $10 \%$ reduction in the total cost for selected inputs (herbicide, insecticide, seed, and nitrogen) is applied to autonomous machinery. In addition, large, heavy farm machinery often contributes to soil compaction resulting in a reduction in yields. The University of Kentucky Extension Services reports a reduction in corn and soybean yields of 7\% due to soil compaction (Murdock and James, 2008). As a result of the lightweight configuration of the autonomous vehicles, soil compaction should be reduced resulting in increased yield potential; therefore, a yield increase of $7 \%$ percent is used for this study.

Given the inclusion of the anticipated quantitative benefits from autonomous machinery, new machinery selection and economic results are determined (Table 3). Four different scenarios are 
represented: base comparison, the inclusion of only a selected input cost reduction, the inclusion of only a yield increase, and the inclusion of all anticipated benefits. The inclusion of all anticipated benefits combines the benefits accrued under the base comparison with a selected input cost reduction and yield increase. For each benefit scenario examined, the optimal number of autonomous machines remains the same as the base comparison; hence, there is no change in machinery operating and ownership costs.

The inclusion of additional anticipated benefits from operating with autonomous machinery increases net returns above those of the base case autonomous machinery scenario. Net returns increase by approximately $6 \%, 15 \%$, and $20 \%$ for each benefit scenario investigated, respectively over those realized under the base autonomous case. Therefore, if operating with autonomous machines provides such additional benefits, the break-even investment price for intelligent control increases dramatically up to U.S.\$160,995. Consequently, it is important to first understand what additional benefits and to what magnitude they will occur because they will have a substantial impact of what manufacturers could charge for and invest in the development autonomous machinery.

In addition, all scenarios incorporating additional benefits increase the minimum and maximum net returns and illustrate the potential for reducing yield risk as represented by a decrease in the coefficient of variation when compared to operating with conventional machinery. This again illustrates the importance of understanding the potential for additional benefits because it could possibly lead to interesting implications such as risk reduction.

Sensitivity Analysis on Farm Size

Sensitivity analyses are conducted to determine the effect farm size has on the increase in net returns above operating with conventional machinery, and the break-even investment price for intelligent, autonomous controls under the four scenarios in this study (Objective 6). Farm size has little impact on net returns over operating with conventional machinery for each scenario (Figure 1). The average increase in net returns across field size is $4 \%, 9 \%, 19 \%$, and $24 \%$ for each autonomous scenario, respectively. The percent increase in net returns did increase dramatically for smaller farm sizes under each scenario. This might be a function of excluding ownership of used machinery in the conventional choice set or the difficulty of machinery sizing for small grain operations. Nonetheless, the results do provide evidence of the potential for greater profitability by operating autonomous machinery on smaller farms due to the ability of smaller farms to capture economies of size with autonomous machinery. 
Figure 1. The percent increase in net returns above operating with conventional machinery based on farm size for the four scenarios examined under risk neutral median $50 \%$ likelihood for days suitable for fieldwork.

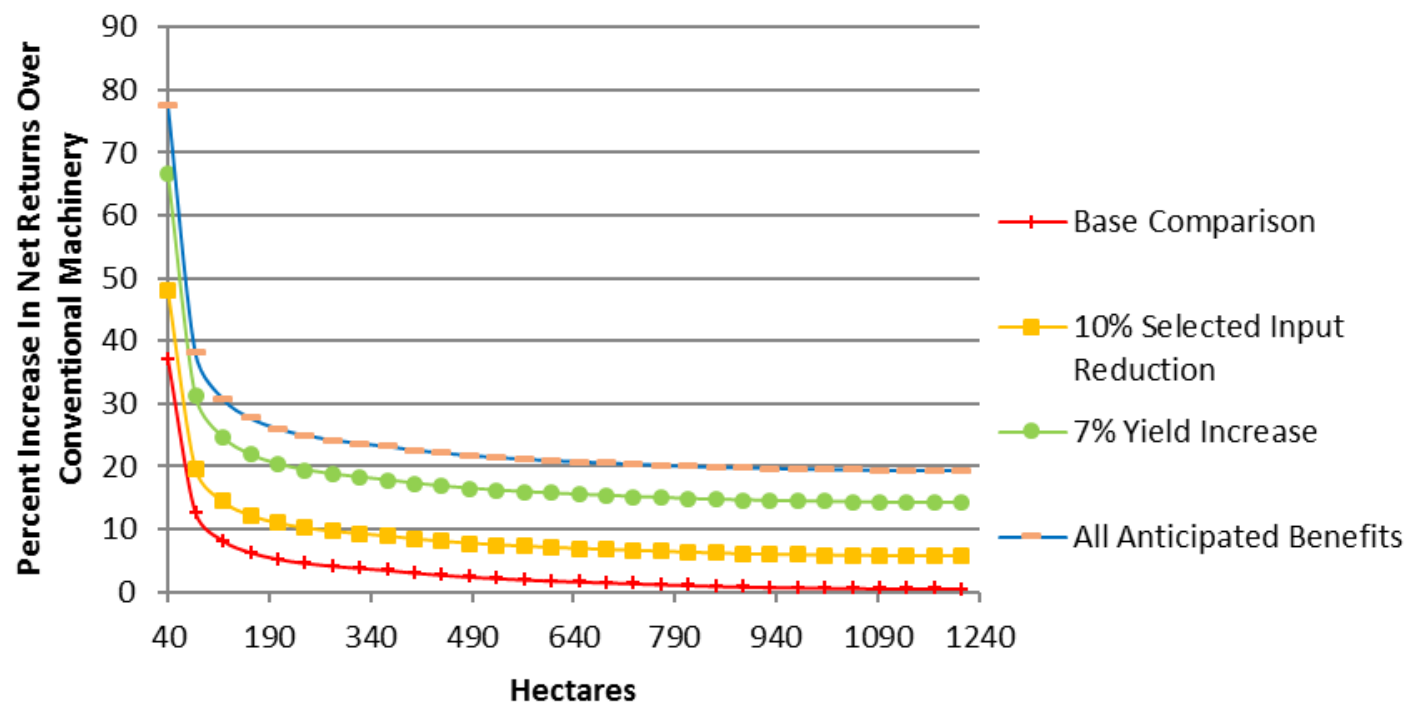

The impact farm size has on the break-even investment price for intelligent, autonomous controls is interesting. The breaks illustrated in Figure 2 represent when an additional autonomous tractor is required to complete the agricultural tasks and represent the integral nature of machinery acquisition. Under each autonomous scenario, the number of autonomous tractors required goes from one to two when farm size was 890 ha. Across all farm sizes examined ( 40 - 1240 ha), the break-even investment prices for intelligent, autonomous controls average U.S.\$23,997, U.S.\$86,209, U.S.\$180,259, and U.S.\$239,106 for each scenario, respectively. In addition, the maximum break-even investment price for intelligent, autonomous controls across farm sizes for each scenario were U.S.\$38,475, U.S.\$160,995, U.S.\$369,493, and U.S. $\$ 498,008$, respectively. Therefore, farm size must be considered when manufacturers determine how much they will be investing in intelligent, autonomous controls. 
Figure 2. The break-even investment price for intelligent, autonomous controls based on farm size for the four scenarios examined under risk neutral median 50\% likelihood for days suitable for fieldwork.

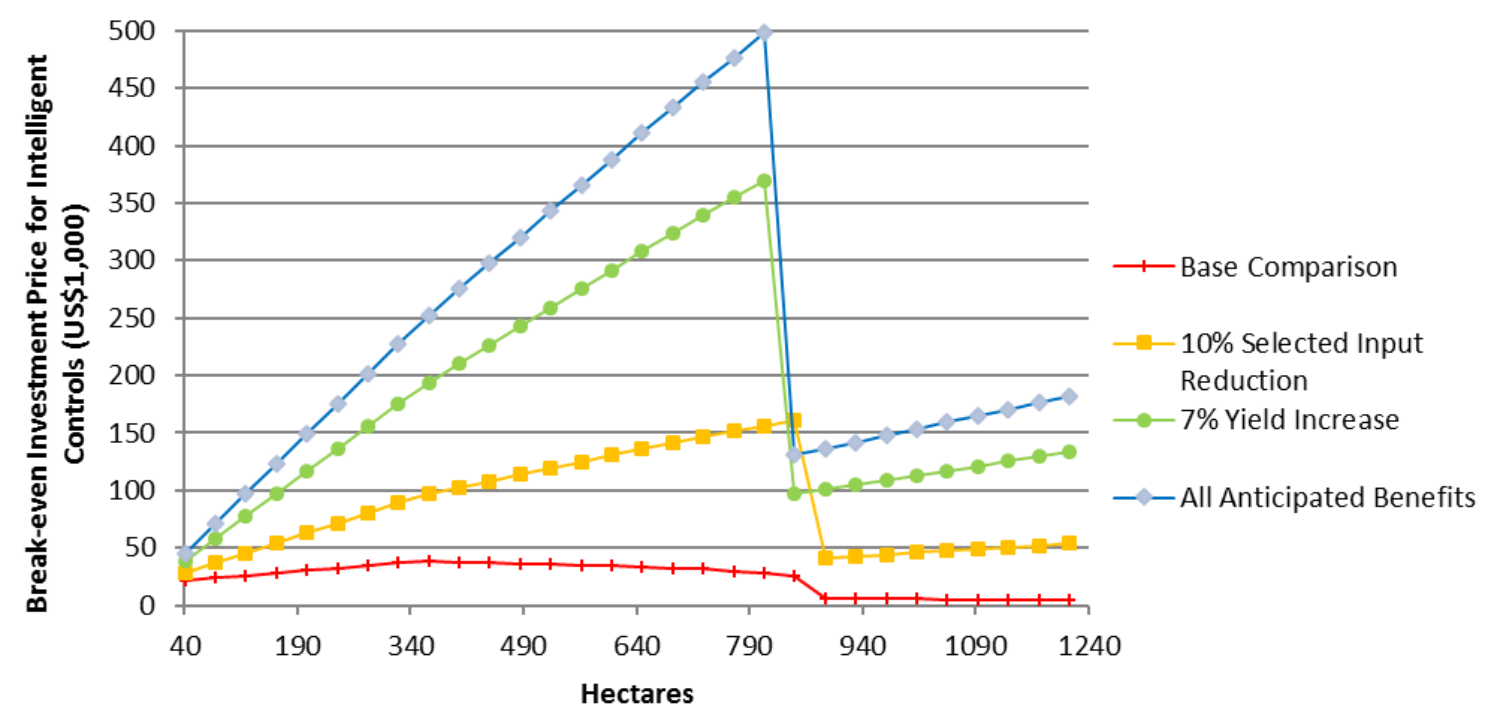

Sensitivity Analysis on Days Suitable for Fieldwork and Grain Prices

Sensitivity analyses are also conducted on days suitable for fieldwork and an increase in grain prices (Objective 7). For the 850 ha base scenario, as days suitable for fieldwork risk increases to mild $(60 \%)$ and moderate $(75 \%)$ risk aversions, two autonomous tractors are required. This is driven by the need to plant in a timely manner as days suitable for fieldwork decrease as risk aversion increases. However, as risk aversion increases, average net returns decreases for autonomous machinery compared to the risk neutral case across all benefit scenarios, while conventional machinery is unaffected. This results in an average net returns over the conventional machinery for mild and moderate risk aversions of U.S.\$4,332 and U.S. $\$ 1,243$, respectively when comparing the base cases. When comparing conventional machinery to the autonomous scenario for which both yield increases and input cost savings are considered, the average net returns for mild and moderate risk aversions are U.S.\$117,802 and U.S.\$114,498, respectively. Therefore, the break-even investment price also decreases across all autonomous scenarios as days suitable for fieldwork risk increases. For moderate risk aversion (75\%) under the base benefits scenario, the breakeven investment price for intelligent autonomous controls is only U.S.\$1,361. However, if both benefits (yield and input cost reduction) are incorporated, the break-even investment price for intelligent autonomous controls for the moderate risk aversion level is U.S.\$129,169.

The impact of farm size on the break-even investment price for intelligent, autonomous controls is investigated under each risk aversion scenario. The mild risk aversion and risk neutral scenarios yield similar results (Figure 3). 
Figure 3. The break-even investment price for intelligent, autonomous controls based on farm size for the four scenarios examined under mild risk averse $60 \%$ likelihood for days suitable for fieldwork.

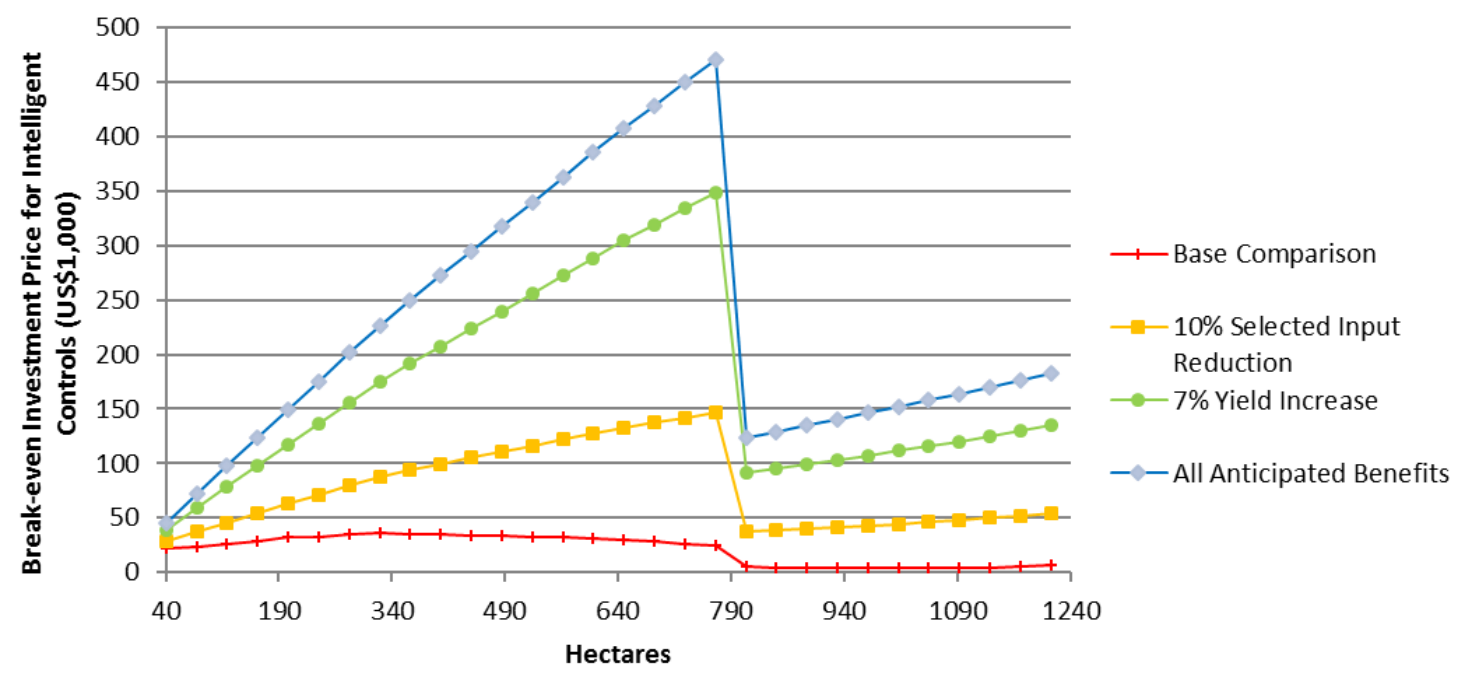

However, an additional autonomous tractor is required at a smaller farm size for the mild risk aversion scenario compared to the risk neutral ( 809 ha vs 890 ha). For the moderate risk aversion level, a second autonomous tractor is required at an even smaller farm size (607 ha) and now a third autonomous tractor is required at 1052 ha. Furthermore, the break-even investment prices are lower across all benefit scenarios for moderate risk aversion compared to both risk neutral and mild risk aversion levels (Figure 4).

Figure 4. The break-even investment price for intelligent, autonomous controls based on farm size for the four scenarios examined under moderately risk averse $75 \%$ likelihood for days suitable for fieldwork.

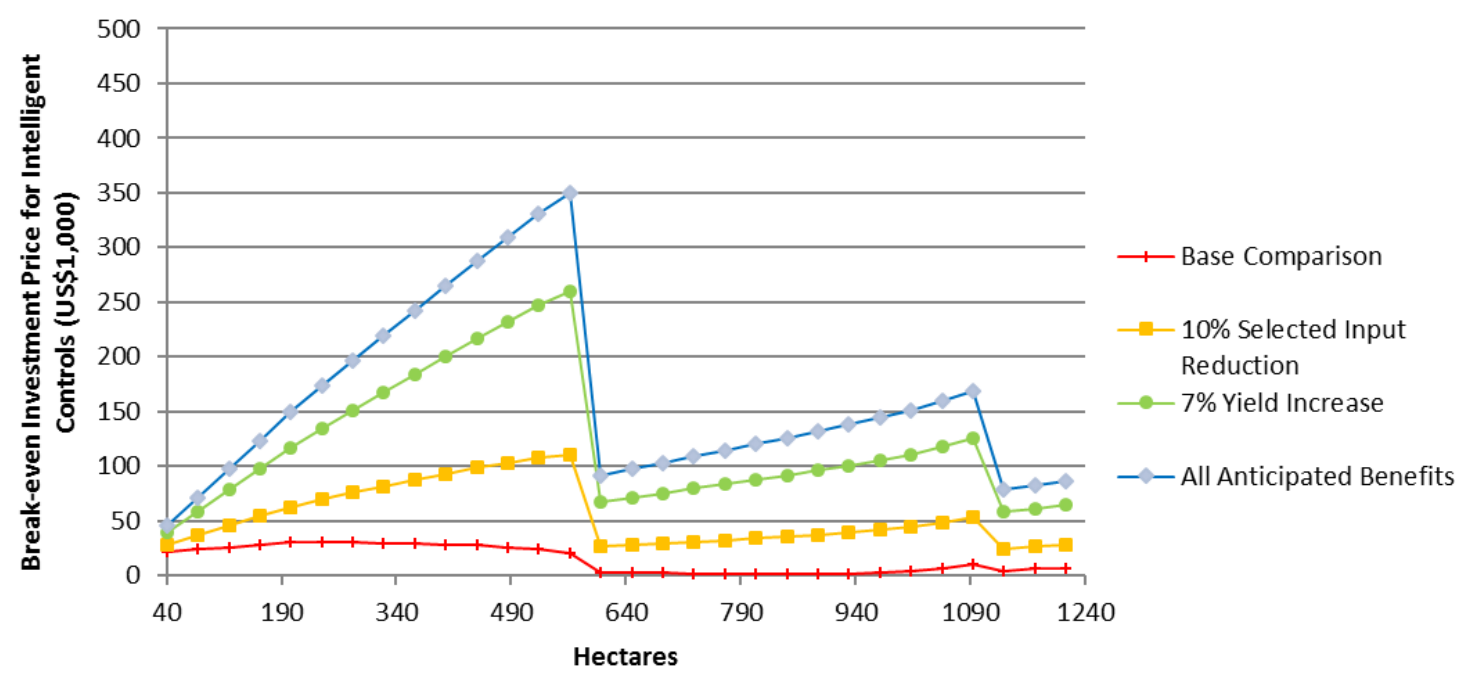


The impact grain prices have on machinery selection, average net returns, and break-even investment price are also explored (Objective 8). If grain prices increased 25 percent from the base in the risk neutral case, the percent increase in net returns over conventional machinery decreases across all scenarios and farm size (Figure 5).

Figure 5. The percent increase in net returns above operating with conventional machinery based on farm size for the four scenarios examined under risk neutral median $50 \%$ likelihood for days suitable for fieldwork and a $25 \%$ increase in grain prices.

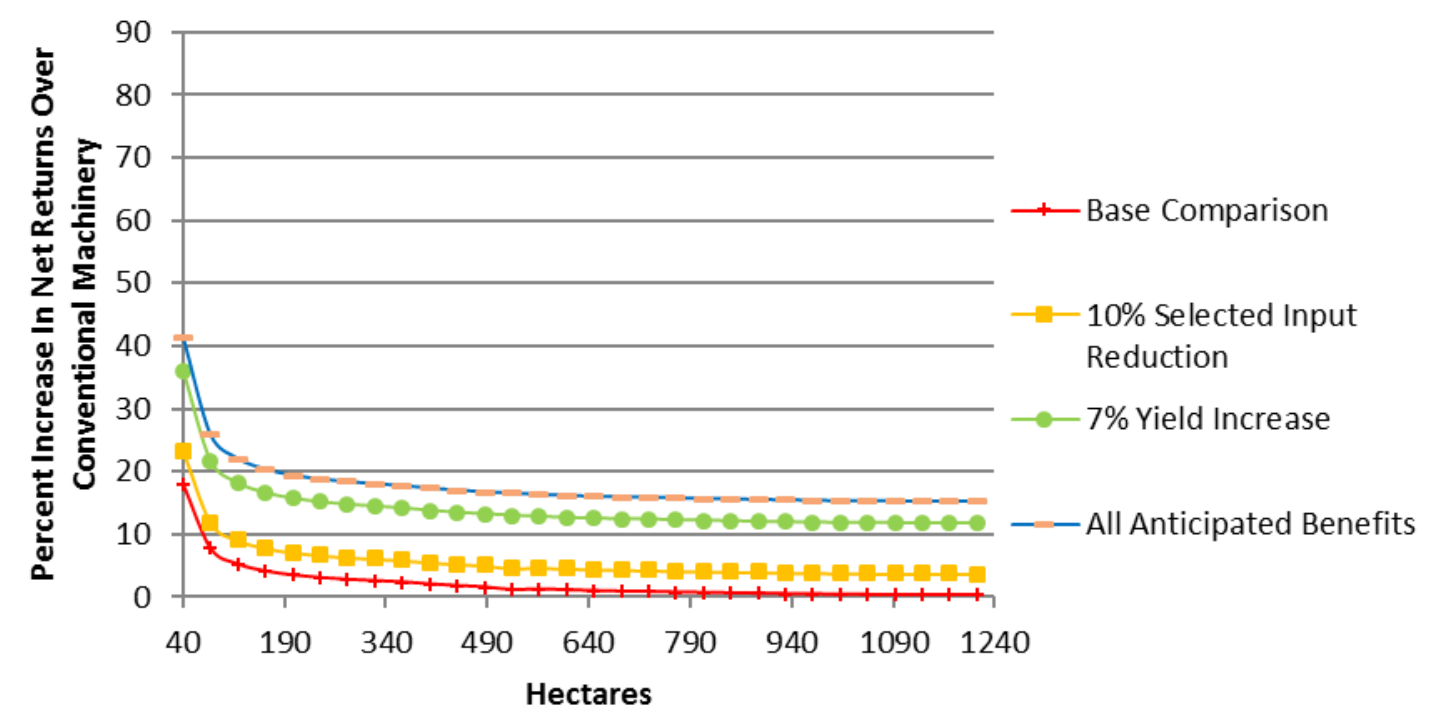

This is especially evident at smaller farm sizes. Furthermore, if grain prices increase 25 percent in the risk neutral case, a third autonomous tractor is required at 1052 ha to plant more at the optimal time and capture the value of increased grain prices (Figure 6). 
Figure 6. The break-even investment price for intelligent, autonomous controls based on farm size for the four scenarios examined under risk neutral median 50\% likelihood for days suitable for fieldwork and a $25 \%$ increase in grain prices.

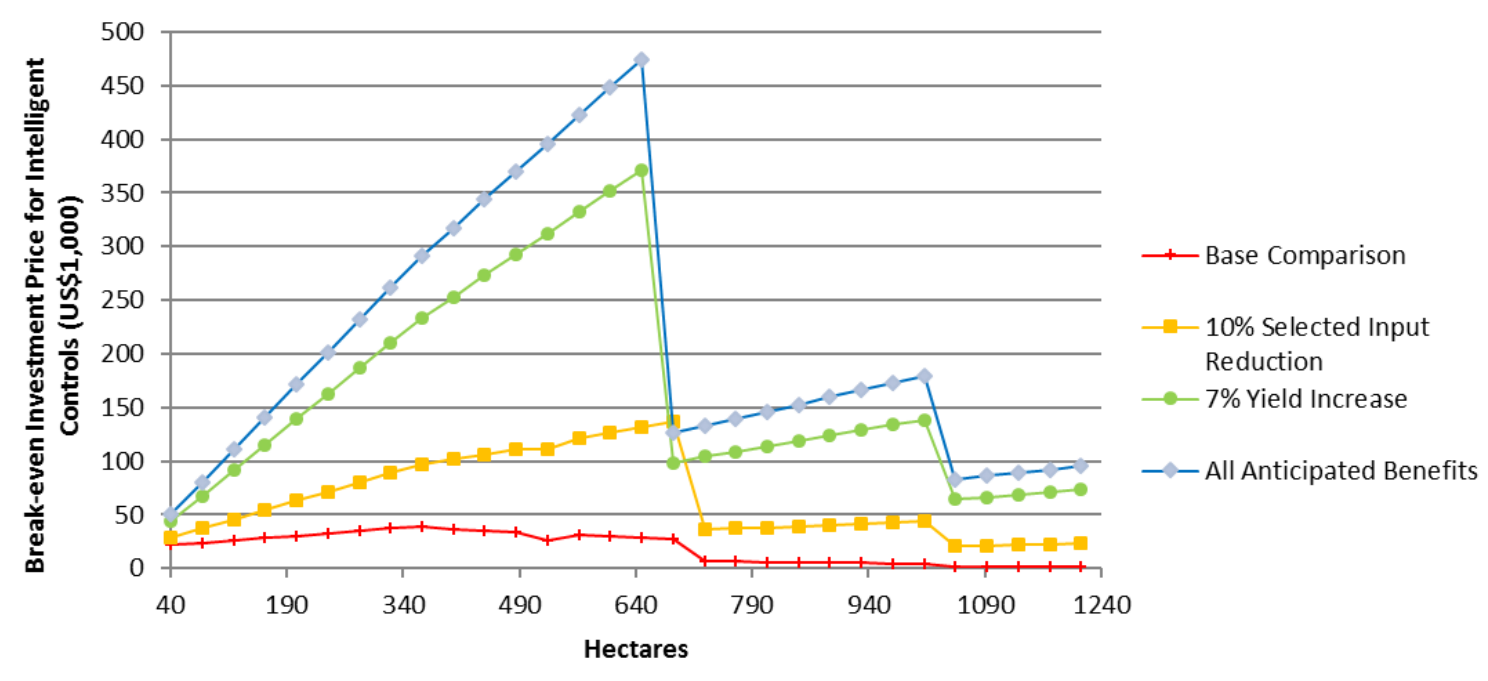

\section{Summary and Conclusions}

The replacement of human operators in agricultural production with advanced technology will lead to changes in the entire structure of agriculture and impact society at a multitude of levels. However, if advanced technologies such as autonomous machinery are not profitable for producers, their impacts will never be realized as these technologies will not be adopted. Therefore, a multifaceted whole farm planning model is developed to compare conventional and autonomous machinery options for a grain crop operation. A mixed integer mathematical programming formulation is developed that incorporated three optimization models: machinery selection, resource allocation, and sequencing. The model determines the optimal conventional machinery complement necessary to perform agricultural tasks common for the farm for various benefit, days suitable for fieldwork, and grain price scenarios. In addition, the model determines the optimal number of autonomous machines to perform the same agricultural tasks for the various scenarios. Given the case study, autonomous machinery is more profitable than conventional machinery for all scenarios. The most costly investment in autonomous machinery is intelligent controls. Therefore, the break-even investment price for intelligent, autonomous controls is determined. If no quantitative benefits are incorporated into the model, the break-even investment price for intelligent, autonomous controls per tractor is U.S. $\$ 26,128$ for the case study and risk neutral days suitable for fieldwork. However, when incorporating additional benefits such as selected input cost savings and increased yields, the breakeven investment price for intelligent, autonomous controls increases dramatically per tractor (up to U.S. $\$ 160,995$ for an 850 ha farm). In addition, sensitivity analyses are conducted to determine the effect 
farm size, days suitable for fieldwork risk aversion, and grain prices have on the increase in net returns above operating with conventional machinery and the break-even investment price for intelligent, autonomous controls. It is concluded that farm size, days suitable for fieldwork risk aversion, and grain prices influence the break-even investment price for autonomous controls and number of autonomous machines required, and must be considered by researchers and manufacturers.

Given that autonomous field machinery can have a profound impact on the structure of agriculture, a host of future research opportunities exists. One apparent area of research concerns the impact on labor markets. By removing operators from agricultural field machinery, opportunities exist to study off-farm income and the impact this will have on rural economic development. The impact of weather uncertainty could be analyzed, including the calculation of the distribution of autonomous machinery investment price resulting in equivalent net present values across various scenarios using Monte Carlo or related simulation. Finally, there are numerous managerial concerns to address for the successful implementation of autonomous machinery.

\section{Acknowledgements}

This research was partially funded by a USDA-CSREES Grant titled "Precision Agriculture: Development and Assessment of Integrated Practices for Kentucky Producers." Any opinions, findings, conclusions, or recommendations expressed in this publication are those of the authors and do not necessarily reflect the views of the U.S. Department of Agriculture.

\section{References}

Astrand, B. and A.J. Baerveldt, 2002. "An Agricultural Mobile Robot with Vision-Based Perception for Mechanical Weed Control." Autonomous Robots 13, 21-35.

Bak, T. and H. Jakobsen, 2004. “Agricultural Robotic Platform with Four Wheel Steering for Weed Detection.” Biosystems Engineering 87(2), 125-136.

Blackmore, B.S. and C.P. Blackmore, 2007. “People, Robots, and Systemic Decision Making.” In: Proceedings of the $6^{\text {th }}$ European Conference on Precision Agriculture, eds. J.V.Stafford, Wageningen Academic Publishers, Skiathos, Greece, 433-439.

Blackmore, B.S., S. Fountas, and H. Have, 2004. "System Requirements for a Small Autonomous Tractor." Agricultural Engineering International: the CIGR Journal of Scientific Research and Development. Manuscript PM 04001.

Charnes, A. and W.W. Cooper. "Chance Constrained Programming.” Management Science 6 (1959): 7379.

Danok, A.B., B.A. McCarl, and T.K. White, 1980. "Machinery Selection Modeling: Incorporation of Weather Variability.” American Journal of Agricultural Economics 62(4), 700-709. 
Dillon, C.R. "Production Practice Alternatives for Income and Suitable Field Day Risk Management." Journal of Agricultural and Applied Economics 31, 2 (1999): 247-61.

Goense, D., 2005 “The Economics of Autonomous Vehicles in Agriculture." Presented at the ASAE Annual International Meeting. Paper Number: 051056. Tampa, Florida.

Gottschalk, R., X.P. Burgos-Artizzu, and A. Ribeiro, 2009. "Development of a Small Agricultural Field Inspection Vehicle." In: Proceedings of the $7^{\text {th }}$ European Conference on Precision Agriculture. Wageningen, Netherlands. July 6-8, pp.877-884.

Griepentrog, H.W., N.A. Andersen, J.C. Andersen, M. Blacke, O. Heinemann, T.E. Madsen, J. Nielsen, S.M. Pedersen, O. Ravn, and D. Wulfsohn, 2009. "Safe and Reliable: Further Development of a Field Robot." In: Proceedings of the $7^{\text {th }}$ European Conference on Precision Agriculture. Wageningen, Netherlands. July 6-8, pp.857-866.

Jones, J.W., G. Hoogenboom, C.H. Porter, K.J. Boote, W.D. Batchelor, L.A. Hunt, P.W. Wilkens, U. Singh, A.J. Gijsman, J.T. Ritchie, 2003. “The DSSAT Cropping System Model.” European Journal of Agronomy 18: 235-265.

Laughlin, D.H. and S.R. Spurlock, 2007. Mississippi State Budget Generator v6.0.

Luck, J.D., A. Sharda, S.K. Pitla, J.P. Fulton, S.A. Shearer, 2011. “A Case Study Concerning the Effects Of Controller Response and Turning Movement on Application Rate Uniformity With a SelfPropelled Sprayer." Transactions of the ASABE 54(2): 423-431.

Marchant, J.A., T. Hague, and N.D. Tillett, 1997. "Row-Following Accuracy of an Autonomous VisionGuided Agricultural Vehicle.” Computers and Electronics in Agriculture 16, 165-175.

Murdock, L.W. and J. James, 2008. “Compaction, Tillage Method, and Subsoiling Effects on Crop Production.” University of Kentucky Cooperative Extension Service Bulletin: AGR-197.

Pedersen, S.M., S. Fountas, and S. Blackmore, 2007. "Economic Potential of Robots for High Value Crops and Landscape Treatment." In: Proceedings of the $6^{\text {th }}$ European Conference on Precision Agriculture, eds. J.V.Stafford, Wageningen Academic Publishers, Skiathos, Greece, 457-464.

Pedersen, S.M., S. Fountas, H. Have, and B.S. Blackmore, 2006. “Agricultural Robots— System Analysis and Economic Feasibility." Precision Agriculture 7, 295-208.

Pitla, S.K., J.D. Luck, and S.A. Shearer, 2010a. "Low Cost Obstacle Detection Sensor Array for Unmanned Agricultural Vehicles." Presented at the 2010 ASABE Annual International Meeting. Paper Number: 1008702. Pittsburgh, Pennsylvania.

Pitla, S.K., J.D. Luck, and S.A. Shearer, 2010b. "Multi-Robot System Control Architecture (MRSCA) for Agricultural Production.” Presented at the 2010 ASABEAnnual International Meeting. Paper Number: 1008702. Pittsburgh, Pennsylvania. 
Piece, J.S. 2018. Kentucky Farm Business Management Program: Annual Summary Data 2017. Lexington,

KY: University of Kentucky Cooperative Extension Service.

Ruckelshausen, A., P. Biber, M. Dorna, H. Gremmes, R. Klose, A. Linz, R. Rahe, R. Resch, M. Thiel, D. Trautz, and U. Weiss, 2009. "BoniRob: An Autonomous Field Robot Platform for Individual Plant Phenotyping." In: Proceedings of the $7^{\text {th }}$ European Conference on Precision Agriculture. Wageningen, Netherlands. July 6-8, pp.841-847.

Schieffer, J. and C.R. Dillon, February 2015. "The Economic and Environmental Impacts of Precision Agriculture and Interactions with Agro-Environmental Policy.” Precision Agriculture. 16,1: 46-61.

Shockley, J.M. and C.R. Dillon. “An Economic Feasibility Assessment for Adoption of Autonomous Field Machinery in Row Crop Production.” Selected Paper prepared for presentation at the 2018 International Conference on Precision Agriculture, Montreal, Quebec. June 24-26, 2018.

Shockley, J.M., C.R. Dillon, T. Stombaugh, and S. Shearer. "Whole Farm Analysis of Automatic Section Control for Agricultural Machinery." Precision Agriculture. 13, 4 (2012): 411-420.

Shockley, J.M., C.R. Dillon, and T. Stombaugh, February 2011. "A Whole Farm Analysis of the Influence of Auto-steer Navigation on Net Returns, Risk, and Production Practices.” Journal of Agricultural and Applied Economics. 43,1: 57-75.

Shockley, J.M. and T.B. Mark. “AEC-101: Days Suitable for Fieldwork in Kentucky.” University of Kentucky Cooperative Extension Service, 2017. Available Online: www.uky.edu/Ag/AgEcon/pubs/extSFW32.pdf

University of Kentucky Cooperative Extension Service Bulletins, 2008. AGR1, AGR129, AGR130, AGR132, ID139 Bulletins. Available Online: http://dept.ca.uky.edu/agc/pub area.asp?area=ANR. van Henten, E.J., C.J. van Asselt, T. Bakker, S.K. Blaauw, M.H.A.M. Govers, J.W. Hofstee, R.M.C. Jansen, A.T. Nieuwenhuizen, S.L. Speetjens, J.D. Stigter, G. van Straten, and L.G. van Willigenburg, 2009. "WURking: A Small Sized Autonomous Robot for the Farm of the Future." In: Proceedings of the $7^{\text {th }}$ European Conference on Precision Agriculture. Wageningen, Netherlands. July 6-8, pp.833-840. Vougioukas, S., 2007. "Path Tracking Control for Autonomous Tractors with Reactive Obstacle Avoidance Based on Evidence Grids." In: Proceedings of the $6^{\text {th }}$ European Conference on Precision Agriculture, eds. J.V. Stafford, Wageningen Academic Publishers, Skiathos, Greece, pp. 483-490. Vougioukas, S., 2009. “A Framework for Motion Coordination of Small Teams of Agricultural Robots.” In: Proceedings of the $7^{\text {th }}$ European Conference on Precision Agriculture. Wageningen, Netherlands. July 6-8, pp.585-593. 